\title{
Whole-Body Vibration Training Improves Balance, Muscle Strength and Glycosylated Hemoglobin in Elderly Patients with Diabetic Neuropathy
}

\author{
Kyoungjin Lee, ${ }^{1}$ Seungwon Lee ${ }^{1}$ and Changho Song ${ }^{1}$ \\ ${ }^{1}$ Department of Physical Therapy, Sahmyook University, Seoul, Republic of Korea
}

\begin{abstract}
Elderly patients with diabetes and peripheral neuropathy are more likely to experience falls. However, the information available on how such falls can be prevented is scarce. We investigated the effects of wholebody vibration (WBV) combined with a balance exercise program on balance, muscle strength, and glycosylated hemoglobin ( $\mathrm{HbA1c}$ ) in elderly patients with diabetic peripheral neuropathy. Fifty-five elderly patients with diabetic neuropathy were randomly assigned to WBV with balance exercise group, balance exercise (BE) group, and control group. The WBV and BE groups performed the balance exercise program for 60 min per day, 2 times per week, for 6 weeks. Further, the WBV group performed WBV training (up to $3 \times 3$ min, 3 times per week, for 6 weeks). The control group did not participate in any training. The main outcome measures were assessed at baseline and after 6 weeks of training; namely, we assessed the postural sway and one leg stance (OLS) for static balance; Berg balance scale (BBS), timed up-and-go (TUG) test, and functional reach test (FRT) for dynamic balance; five-times-sit-to-stand (FTSTS) test for muscle strength; and $\mathrm{HbA} 1 \mathrm{c}$ for predicting the progression of diabetes. Significant improvements were noted in the static balance, dynamic balance, muscle strength, and HbA1c in the WBV group, compared to the $\mathrm{BE}$ and control groups $(P<0.05)$. Thus, in combination with the balance exercise program, the shortterm WBV therapy is beneficial in improving balance, muscle strength and $\mathrm{HbA} 1 \mathrm{c}$, in elderly patients with diabetic neuropathy who are at high risk for suffering falls.
\end{abstract}

Keywords: balance; diabetic neuropathy; elderly; fall; whole-body vibration

Tohoku J. Exp. Med., 2013 December, 231 (4), 305-314. C C 2013 Tohoku University Medical Press

\section{Introduction}

Each year, one-third of individuals aged over 65 years of age experience a fall, and $10-15 \%$ of these falls result in serious injuries, such as fractures and/or head injuries (Hausdorff et al. 2001). The physical and psychological after-effects of falls in the elderly can cause more serious problems than the falls themselves (Gillespie et al. 2009). Elderly people consequently develop a fear of falling and psychological distress. Furthermore, recovery from fallrelated injuries typically needs a period of prolonged immobility (Delbaere et al. 2006), which triggers a vicious circle of increased dependency with respect to the activities of daily living and deteriorations in body functions (Verghese et al. 2009).

Elderly people with chronic diseases are more prone to serious damage and complications after a fall. For example, diabetic patients with complications, such as peripheral neuropathy, visual defects, poor kidney function, and hypoglycemia, are likely to experience various physical and psychological limitations and difficulties (Snowling and
Hopkins 2006; Schwartz et al. 2008). Interactions between the vestibular system and cerebellum, which regulate the musculoskeletal and sensorimotor systems, are responsible for balance (Horlings et al. 2009). Peripheral neuropathy, a complication of diabetes, negatively affects proprioception and increases postural instability or body sway (Ites et al. 2011). Delayed reaction and recovery times from sudden postural changes on irregular surfaces comprise further risk factors for falls (Lord and Castell 1994). In fact, the incidence rate of falls in elderly individuals with diabetes is $78 \%$ as compared to $30 \%$ in healthy elderly individuals; further, the fall risk rate is 1.5 times higher in elderly patients with diabetic neuropathy than in normal people (Yamamoto et al. 2001; Duby et al. 2004; Volpato et al. 2005). Elderly individuals with diabetic peripheral neuropathy tend to exhibit greater postural sway and imbalance because of delayed reactions to stimuli. This prolongation in reaction times keeps elderly individuals with diabetic neuropathy from responding rapidly and accurately to sudden postural changes, which may directly increase the fall risk (Menz et al. 2004).

Received September 11, 2013; revised and accepted November 26, 2013. Published online December 14, 2013; doi: 10.1620/tjem.231.305.

Correspondence: Changho Song, P.T., Ph.D., Department of Physical Therapy, Sahmyook University, 26-21 Gongneung 2-dong,

Nowon-gu, Seoul 139-742, Republic of Korea.

e-mail: chsong@syu.ac.kr 
It has been demonstrated that exercises that improve balance aid in preventing falls in elderly individuals (Lopopolo et al. 2006). Regular exercise effectively improves balance capacity by reducing postural sway, increasing flexibility, and strengthening lower-limb muscles (Jessup et al. 2003). Although one study has investigated the effects of such exercise interventions in elderly patients with diabetic neuropathy, their results have not been adequately confirmed (Song et al. 2011).

Moreover, most such studies have focused on glycemic control and the risk of cardiovascular disease, with relatively few reports focusing on fall prevention (Richardson et al. 2001; Maiorana et al. 2002; Snowling and Hopkins 2006). Therefore, systematic research is needed to verify the effects of exercises designed to prevent falls in elderly individuals with diabetic neuropathy (Ites et al. 2011).

Whole-body vibration (WBV) therapy has recently attracted renewed interest as a method for treating elderly individuals and patients with nervous and/or musculoskeletal defects; one report has described the efficacy of a shortterm WBV program in improving lower-limb muscle strength and power, bone density, and functional mobility, as well as in preventing falls in the elderly (Sitja-Rabert et al. 2012). Another study has compared patients who underwent WBV plus exercises with sedentary control groups; however, this disallowed definitive conclusions regarding the contribution of WBV to musculoskeletal improvements (Roelants et al. 2004). However, a study involving a 10 -week WBV program in female elderly individuals reported positive gains in lower-limb muscle strength and functional mobility (Machado et al. 2010). Interestingly, all relevant, appropriately controlled studies have reported that WBV intervention effectively prevents falls by improving balance in the elderly (Pollock et al. 2012).

WBV plus exercise programs have been demonstrated to be more effective than balance training alone for improving factors related to balance, muscle strength, and falls (Bautmans et al. 2005; Rees et al. 2009). The potential to improve power, functional mobility, and balance, along with the possible benefits for bone strength, suggest that WBV is an effective intervention for preventing falls and fragility fractures (Pollock et al. 2012). However, no study has been conducted to verify the effects of WBV in elderly patients with diabetic neuropathy.

Therefore, we investigated the effects of WBV plus a balance exercise program on balance and strength in elderly individuals with diabetic neuropathy who are at high risk for falls due to reduced physical functions and the complications of underlying diseases. We hypothesize that subjects who undergo a WBV plus a balance program will show greater improvements in the balance and strength compared to subjects who undergo no WBV.

\section{Subjects and Methods}

Participants

We recruited 95 elderly patients with physician-diagnosed diabetic peripheral neuropathy by using flyers at a $\mathrm{G}$ senior health center in South Korea.

The following inclusion criteria were applied: age $\geq 65$ years, either two or more falls during the previous 12 months or one fall plus a timed-up to go (TUG) test result of $>15 \mathrm{sec}$ (a simple, sensitive, and specific cut-point for high-risk fallers) or recurrent unexplained falls. Participants were excluded if they had any musculoskeletal impairment (such as inability to walk independently), neurological impairment, vision impairment, or vestibular diseases with a diabetes-related etiology, or dementia (Mini-Mental State Examination score $<24 / 30$ ). Individuals that participated in less than $80 \%$ of the exercise program and those who were unable to perform follow-up tests were also excluded from the final analyses.

All experimental protocols and procedures were explained to each subject and approved by the institutional review board of Sahmyook University, Korea. All subjects provided written informed consent prior to study enrollment.

Sixty subjects who met the inclusion criteria were randomly divided into three groups, namely, a WBV plus balance exercise group (WBV group, $n=20$ ), a balance exercise group (BE group, $n=$ $20)$, and a control group $(n=20)$ using Random Allocation Software (version 1.0) (Saghaei 2004). However, one subject from the WBV group was excluded due to a program participation rate of $<80 \%$, two in the BE group were excluded because of fractures requiring hospitalization, and two in the control group were excluded because of home relocation. Accordingly, the study cohort comprised 55 subjects: 19 in the WBV group, 18 in the BE group, and 18 in the control group. No significant differences were observed among the three groups for sex, age, height, weight, experience of falls, duration of diabetes, or treatment (Table 1, Fig. 1).

\section{Intervention and Measurement}

All the WBV and BE participants underwent a physical therapist-supervised 60-min balance exercise program twice per week, which combined progressive strength, balance, and functional mobility training, for 6 weeks. The WBV group also underwent WBV therapy thrice per week.

The balance exercise program was designed based on exercises previously shown to improve balance (Richardson et al. 2001; Song et al. 2011). The exercise comprised $10 \mathrm{~min}$ of warm-up activities, 40 min of balance training, and 10 min of cool-down activities.

Warm-up included gentle stretching, forward, backward, and sideways step-ups on foam and massage with a sensory ball, all performed to light smoothing music. This warm-up was performed to increase muscle flexibility.

The balance training consisted of three parts. The exercise interventions were performed on a high-elasticity balance-training mat. Static exercise on a training mat comprised heel and toe raises, one-legged stance for each limb, weight shifting forward, backward, sideward and diagonally, and turning the head to the left and then to the right keeping the feet together. This exercise comprised two 10-min sessions each, with eyes opened and eyes closed, respectively. While performing the second set of exercises, patients were paired for safety reasons and they performed in turns. Dynamic exercise on the training mat involved walking, step-ups, and bipedal jumps for 10 min. Progressive balance exercises on the training mat involved narrow walking, walking backward, walking sideward, stepping over obstacles, stepping on obstacles, passing balls arranged on the training mat in a circle, and throwing and catching a ball on the training 
Table 1. Description of Subject's Baseline Characteristics $(N=55)$.

\begin{tabular}{lcccc}
\hline & WBV group & BE group & control group & $p$ \\
\hline Gender (male/female) & $19(9 / 10)$ & $18(7 / 11)$ & $18(8 / 10)$ & $\mathrm{ns}$ \\
Age (year) & $76.31 \pm 4.78^{\mathrm{a}}$ & $74.05 \pm 5.42$ & $75.77 \pm 5.69$ & $\mathrm{~ns}$ \\
Height $(\mathrm{cm})$ & $156.26 \pm 6.83$ & $157.00 \pm 7.85$ & $159.61 \pm 8.41$ & $\mathrm{~ns}$ \\
Weight $(\mathrm{kg})$ & $61.84 \pm 9.41$ & $62.11 \pm 9.44$ & $62.27 \pm 10.09$ & $\mathrm{~ns}$ \\
HbAlc & $7.08 \pm 1.18$ & $6.99 \pm 1.05$ & $6.93 \pm 1.13$ & $\mathrm{~ns}$ \\
Duration of diabetes (year) & $13.24 \pm 4.32$ & $12.29 \pm 4.98$ & $11.27 \pm 5.78$ & $\mathrm{~ns}$ \\
Number of falls $(n)$ & $1.26 \pm 0.56$ & $1.33 \pm 0.49$ & $1.39 \pm 0.70$ & $\mathrm{~ns}$ \\
\hline
\end{tabular}

${ }^{a}$ mean \pm standard deviation, ns, not significant.

WBV group, whole-body vibration plus balance exercise group; BE group, balance exercise group.

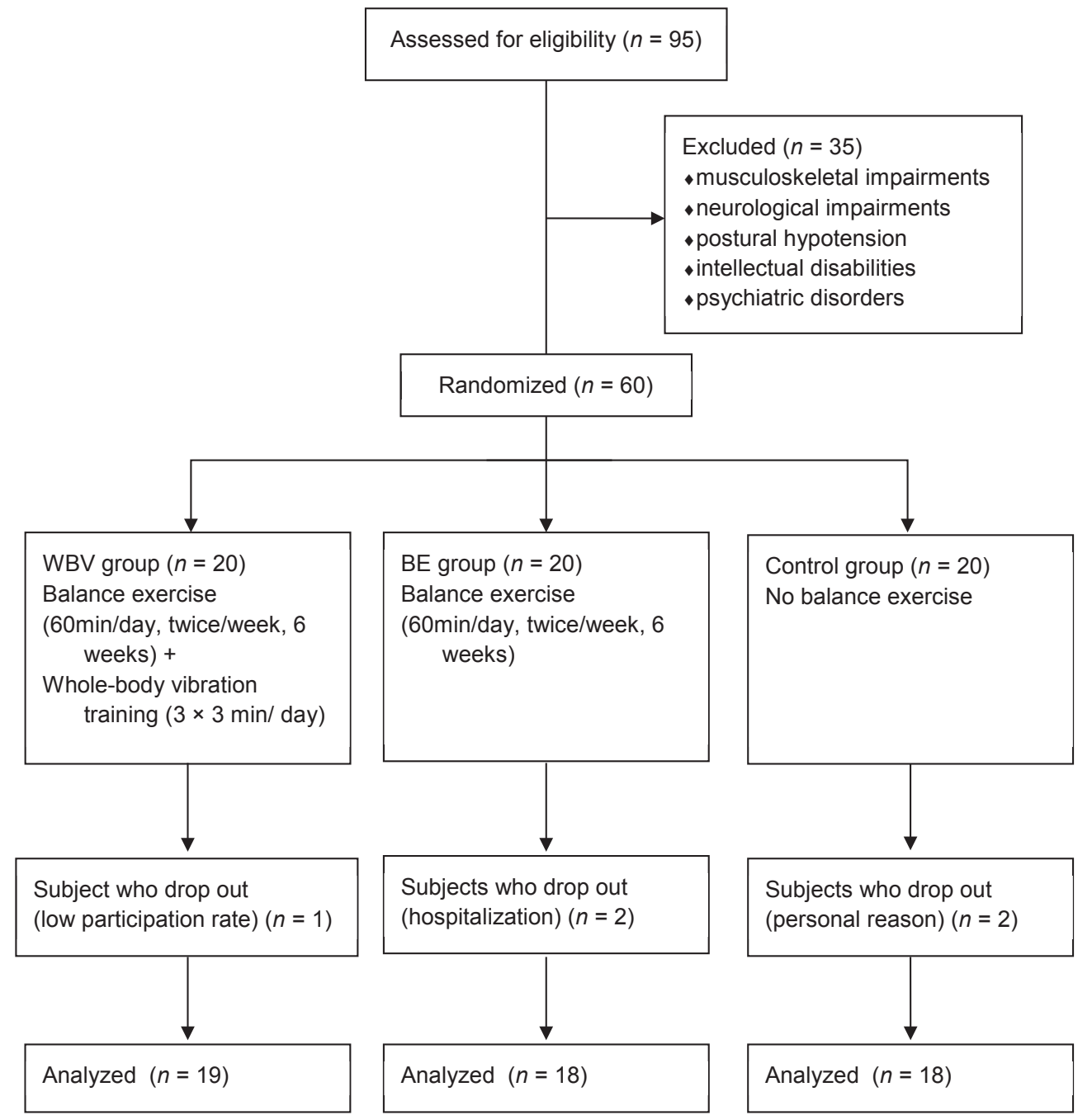

Fig. 1. Flowchart of participants of the study.

mat for $10 \mathrm{~min}$.

Following balance training, cool-down exercises were performed to prevent muscle fatigue and sudden hypoglycemia, to relax tensed muscles, and to help return the heart and respiratory rates to normal. These exercises included deep breathing, abdominal breathing, and static back extensor exercises in a reclined position.

All exercises were performed in pairs such that when one per- son was exercising, another was supervising to ensure that exercises were performed correctly. After every exercise session, subjects were allowed 2-min rest periods (especially during the first and second part) during which they performed upper limb exercises with a Theraband while sitting on a chair. Identical training products were used for all participants (high-elasticity balance training mat (StimUp, Alfoots, Korea): $46 \times 496 \times 6 \mathrm{~cm}$; polyurethane foam ball 
(Polyurethan soft ball; EDUFOAM, Korea): diameter, $17 \mathrm{~cm}$; yellow Theraband (Thera-band; Hygenic Corporation, USA): length, $40 \mathrm{~cm}$ and resistance, $1 \mathrm{~kg}$ ).

The WBV training was performed on a vibration platform (Galileo 2000, Novotec Medical GmBH, Germany). WBV training was conducted on an individual basis in a private room under the supervision of a researcher. Subjects stood upright on the platform, and were vibrated in a $110^{\circ}$ squatting position, over clearly marked foot positions, wearing normal footwear, and using a handrail for support if required (Behboudi et al. 2011). Lower frequencies and amplitudes ( $15 \mathrm{~Hz}$ and peak-to-peak amplitude of $2 \mathrm{~mm}$ ) were used initially for familiarization. Thereafter, to obtain greater muscular response (Pollock et al. 2010), WBV training was performed at a frequency of $15-30 \mathrm{~Hz}$ and amplitude of $1-3 \mathrm{~mm}$. The exercise comprised $3 \times$ 3-min bouts of WBV with 1-min intervals between bouts (Von Stengel et al. 2011). Subjects exercised at $15 \mathrm{~Hz}$ during the 1st week, $20 \mathrm{~Hz}$ in the 2nd and 3rd weeks, $25 \mathrm{~Hz}$ in the 4th and 5th weeks, and at $30 \mathrm{~Hz}$ in the 6 th week.

Evaluations were performed twice, before (baseline) and after 6 weeks of exercise. Evaluations were performed by an assessor blinded to study details.

To evaluate the degree of diabetes, we examined HbAlc. $\mathrm{HbA} 1 \mathrm{c}$ is a form of hemoglobin that is measured primarily to identify the average plasma glucose concentration over prolonged periods. The subject's disease status was evaluated by checking the value of total $\mathrm{HbA1c}$, measured using low-pressure cation exchange chromatography (reference range: 5-8.6\%, Ciba Corning 765 Glycomat; Palo Alto, CA). HbA1c levels represent a 2-3-month average of blood glucose concentrations. This cutoff was defined a priori to achieve good diagnostic specificity. HbAlc levels were assessed by reviewing the participants' medical records. The Microparticle Enzyme Immunoassay method was applied, using the variant II HbA1c T-kit for 3-cc venous blood samples; all evaluations were performed by the Korean Green Cross Corporation Center, Korea. Concentrations below $6.5 \%$ are considered normal, while the target concentration of $\mathrm{HbA} 1 \mathrm{c}$ for patients with diabetes is $\sim 7.0 \%$. Test-retest reliability in the present study indicated temporal stability $(r=0.73)$.

Postural sway was measured using a force platform (Good Balance, Metitur, Jyväskylä, Finland). From movements of the center of pressure, three different balance outcome variables were calculated for all standing balance tests, that is, antero-posterior (AP) sway velocity, medio-lateral (ML) sway velocity, and velocity moment (Era et al. 1996). The subjects stood comfortably on the platform without shoes with arms at their sides for $30 \mathrm{sec}$. Results represent the average of 3 consecutive measurements. These tests have high intra rater reliability (0.78-0.96) and inter rater reliability (0.16-0.81). Therefore, for assessing static balance, this test has high reliability and internal validity (Punakallio 2004; Paltamaa et al. 2005).

The one leg stance (OLS) test was used to assess postural balance. Each subject was instructed to maintain balance on the nondominant leg with eyes opened, eyes closed, and arms spread for as long as possible. The time taken for the contralateral foot to touch the ground was measured in seconds using a stopwatch (HS-70W1DF, Casio, Japan). This test was performed twice, and the highest score was recorded (Resnick et al. 2000).

Berg balance scale (BBS), developed to measure balance in elderly individuals based on assessments of functional tasks, is a valid instrument for evaluating the effectiveness of interventions and for providing quantitative descriptions of physiological function in clini- cal practice and research (Berg et al. 1992).

The functional reach test (FRT) evaluates the limits of physical stability and is used to measure dynamic balance and flexibility during the performance of functional tasks (Duncan et al. 1990). Subjects were instructed to stand with feet at shoulder width and to lift arms parallel to shoulder height (shoulders were prevented from bending forward or backward) with arms stretched out as far as possible. Then, the distance of moving the knuckle's end was measured. Measurements were conducted in centimeters; a longer distance represented better balance ability. Results represent the average of three consecutive measurements.

TUG test is a test of balance commonly used to examine functional mobility in community-dwelling, frail older adults. This test measures the time taken by an individual to stand up from a standard arm chair (approximate seat height, $46 \mathrm{~cm}$ ), walk a distance of $3 \mathrm{~m}$, turn, walk back to the chair, and sit down wearing his/her regular footwear and using his/her customary walking aid (cane, walker, etc.). No physical assistance is given. The total time taken to complete the circuit is measured in seconds with a stopwatch. The test was repeated 3 times, and the results were averaged.

To evaluate lower-limb muscle strength, the five-times-sit-tostand (FTSTS) test was used. For this test, the subject was asked to sit in an armless chair (with its back supported against a wall) with arms crossed over his/her chest and then instructed to stand and sit five times as quickly as possible. The same chair was used for all subjects. Subjects performed two timed trials. The instructor commenced the test with "Ready, Set, Go", started a digital stopwatch on "Go," and counted aloud each of the five completed sit to stand cycles. The stopwatch was stopped when the subject returned to the seated position for the fifth time (Lord et al. 2002).

\section{Data analysis}

Statistical analyses were performed using SPSS version 19.0 software. The Shapiro-Wilks test was used to evaluate the normal distribution of all parameters. When data were normally distributed, one-way analysis of variance (ANOVA) was used to test for differences in continuous variables between groups, and Student's paired t-test was used to test for differences in continuous variables within groups. Post-hoc analyses were performed using Scheffe's test. Differences between categorical variables were analyzed using the $\chi^{2}$ test. $P<0.05$ was considered statistically significant.

\section{Results}

HbA1c levels showed significant improvement in the WBV group $(p<0.05)$ but not in the BE and control groups. Further, HbA1c levels were significantly improved in the WBV group as compared with the BE and control groups. No significant improvement was noted in the $\mathrm{BE}$ group as compared with the control group (Table 2).

The postural sway in all conditions as well as the results for BBS, TUG, and FTSTS showed significant improvements in the WBV and BE groups $(p<0.05)$ but not in the control group. Postural sway in all conditions showed a significant improvement in the WBV group as compared with the $\mathrm{BE}$ and control groups. No significant improvement was observed in the BE group as compared with the control group.

OLS and FRT showed significant improvements in the 
Table 2. Comparison of HbA1c within groups and between groups $(N=55)$.

\begin{tabular}{|c|c|c|c|c|c|}
\hline & & $\begin{array}{c}\text { WBV group (A) } \\
n=19\end{array}$ & $\begin{array}{c}\text { BE group (B) } \\
n=18\end{array}$ & $\begin{array}{c}\text { control group (C) } \\
n=18\end{array}$ & $\begin{array}{c}\mathrm{F}(p) \\
\text { post hoc }\end{array}$ \\
\hline \multirow{4}{*}{$\mathrm{HbA} 1 \mathrm{c}$} & Pre & $7.08 \pm 1.18^{\mathrm{a}}$ & $6.99 \pm 1.05$ & $6.93 \pm 1.13$ & $0.085(.919)$ \\
\hline & Post & $7.03 \pm 1.16$ & $7.01 \pm 1.01$ & $6.94 \pm 1.12$ & \\
\hline & Post-Pre & $-0.06 \pm 0.10$ & $0.02 \pm 0.19$ & $0.01 \pm 0.13$ & $\begin{array}{c}3.101(.490) \\
\text { A | B C }\end{array}$ \\
\hline & $t(p)$ & $2.625(.017)$ & $0.382(.708)$ & $0.181(.859)$ & \\
\hline
\end{tabular}

${ }^{a}$ mean \pm standard deviation.

WBV group, whole-body vibration plus balance exercise group; BE group, balance exercise group.

WBV and BE groups $(p<0.05)$ but not in the control group. Moreover, the OLS results showed significant improvements in the WBV and BE groups as compared with the control group, and the WBV group showed a significant improvement as compared with the $\mathrm{BE}$ group (Tables 3-6).

\section{Discussion}

This study demonstrates the beneficial effects of WBV plus a balance exercise program in elderly patients with diabetic neuropathy. A 6-week balance exercise program involving WBV significantly improved $\mathrm{HbAlc}$ levels, balance, and muscle strength. Falls can result from various causes, and the tools to assess fall risk vary greatly. In this study, diverse methods were used to evaluate the effects of the interventions used.

The HbAlc, which is used as a predictor for the progression of diabetes, is a method of monitoring blood sugar imbalance as well as evaluating the risk of diabetic complications (Menz et al. 2004). This study revealed a significant decrease of $0.8 \%$ in the WBV group as compared to the other groups, which showed an increase of $0.2 \%$. In a previous study wherein intervention exercises for diabetes were applied at an intensity of $40-50 \%$ for less than 8 weeks, no significant improvement in $\mathrm{HbAlc}$ was observed (Ishii et al. 1998). A recent study reported a significant decrease in HbA1c after performing high-intensity resistance exercises in older patients with type 2 diabetes for over 3 months (Tinetti 2003). Because HbA1c measures the blood sugar level over the previous 2-3 months, a significant change in this parameter can be expected following a long-term intervention. However, in this study, a short-term high-intensity intervention combined with WBV resulted in a significant decrease in $\mathrm{HbA} 1 \mathrm{c}$. Furthermore, the decrease of $0.8 \%$ was considerably significant as compared with previous reports.

In this study, the exercise program was designed based on considerations of postural balance and lower-limb muscle strength as factors for fall prevention. In particular, postural balance is closely correlated with fall risk. Here, static balance was assessed using AP postural sway velocity, ML postural sway velocity, and velocity moment as measured using a force platform. Postural sway is known to be greater in elderly individuals than in young adults and has been demonstrated to be greater in elderly individuals who have experienced a fall than in those who have not (Tinetti 2003; Lajoie 2004). In the WBV group, postural sway decreased by $36 \%$ with eyes open and by $40 \%$ with eyes closed following 6-week training; further, this decrease was considerably greater in the WBV group as compared to that in the other groups. Because ML postural sway is highly correlated with fall risk, the decreases in ML postural sway observed in the present study are considered to be clinically meaningful (Maki et al. 1994; Stel et al. 2003). Furthermore, a number of studies concerning fall prevention in the elderly have repeatedly emphasized that a decrease in postural sway is substantially correlated with fall prevention (Allet et al. 2010; Cakrt et al. 2010).

This study also used OLS, which is a widely used clinical tool for assessing static balance. OLS time showed significant decreases of $36 \%$ with eyes open and $39 \%$ with eyes closed in the WBV group. Previous studies on interventions in the elderly have reported significant increases in OLS time; further, a study focusing on elderly patients with diabetic neuropathy reported a postintervention increase of $46 \%$ in OLS time (Kruse et al. 2010). The balance exercise program applied in the present study included various movements involving the shifting of weight in the forward, backward, sideward, and diagonal directions, all of which improve static balance. Thus, the addition of proprioception stimulation through WBV was considered to have achieved further improvements.

The BBS, FRT, and TUG tests are clinical methods for assessing dynamic balance and are used to predict the risk of falling (Persad et al. 2010). These tests are widely used in the clinical setting because they are convenient and economically feasible. In the present study, they were used to determine improvements in dynamic balance achieved by WBV and the balance exercise program.

This study demonstrated that WBV plus a balance exercise program significantly improved BBS scores. However, previous studies have reported little or no improvement in BBS scores due to a ceiling effect, whereas several others have reported improvements in BBS scores following various intervention methods (Wolf et al. 2001; Steadman et al. 2003; Madureira et al. 2007). Baseline values of BBS scores in the present study ranged from 48 to 50 points, which would explain a ceiling effect, because 
Table 3. Comparison of postural sway within groups and between groups $(N=55)$.

\begin{tabular}{|c|c|c|c|c|c|c|}
\hline & & & $\begin{array}{c}\text { WBV group (A) } \\
n=19\end{array}$ & $\begin{array}{c}\mathrm{BE} \text { group }(\mathrm{B}) \\
n=18\end{array}$ & $\begin{array}{c}\text { control group }(\mathrm{C}) \\
n=18\end{array}$ & $\begin{array}{c}\mathrm{F}(p) \\
\text { post hoc }\end{array}$ \\
\hline \multirow{12}{*}{$\mathrm{EO}$} & \multirow{4}{*}{$\begin{array}{c}\mathrm{AP} \\
(\mathrm{mm} / \mathrm{s})\end{array}$} & Pre & $10.96 \pm 4.27^{\mathrm{a}}$ & $10.55 \pm 4.10$ & $10.50 \pm 4.77$ & $0.060(.942)$ \\
\hline & & Post & $6.91 \pm 3.76$ & $8.51 \pm 4.49$ & $9.15 \pm 5.00$ & \multirow{3}{*}{$\begin{array}{c}14.762(.000) \\
\mathrm{A} \mid \mathrm{B} C\end{array}$} \\
\hline & & Post-Pre & $-4.05 \pm 2.09$ & $-2.05 \pm 3.09$ & $-1.35 \pm 3.93$ & \\
\hline & & $t(p)$ & $8.440(.001)$ & $2.834(.012)$ & $1.466(.162)$ & \\
\hline & \multirow{4}{*}{$\begin{array}{c}\mathrm{ML} \\
(\mathrm{mm} / \mathrm{s})\end{array}$} & Pre & $7.23 \pm 2.78$ & $7.09 \pm 2.38$ & $7.26 \pm 2.77$ & $0.022(.978)$ \\
\hline & & Post & $4.86 \pm 2.66$ & $6.12 \pm 2.48$ & $7.40 \pm 2.61$ & \multirow{3}{*}{$\begin{array}{l}4.699(.011) \\
\mathrm{A} \mid \mathrm{B} \text { C }\end{array}$} \\
\hline & & Post-Pre & $-2.36 \pm 1.80$ & $-0.97 \pm 1.89$ & $0.13 \pm 2.30$ & \\
\hline & & $t(p)$ & $5.712(.000)$ & $2.190(.044)$ & $0.242(.242)$ & \\
\hline & \multirow{4}{*}{$\begin{array}{c}\mathrm{VM} \\
\left(\mathrm{mm} / \mathrm{s}^{2}\right)\end{array}$} & Pre & $28.11 \pm 11.34$ & $27.83 \pm 14.93$ & $28.39 \pm 13.42$ & \multirow[t]{2}{*}{$0.008(.992)$} \\
\hline & & Post & $21.21 \pm 11.71$ & $24.64 \pm 15.08$ & $25.92 \pm 13.75$ & \\
\hline & & Post-Pre & $-6.90 \pm 3.82$ & $-3.19 \pm 6.22$ & $-2.47 \pm 9.32$ & \multirow[t]{2}{*}{$\begin{array}{c}4.699(.011) \\
\text { A | B C }\end{array}$} \\
\hline & & $t(p)$ & $7.880(.000)$ & $2.187(.044)$ & $1.129(.276)$ & \\
\hline \multirow{12}{*}{$\mathrm{EC}$} & \multirow{4}{*}{$\begin{array}{c}\mathrm{AP} \\
(\mathrm{mm} / \mathrm{s})\end{array}$} & Pre & $14.09 \pm 5.27$ & $14.34 \pm 4.86$ & $14.29 \pm 5.66$ & $0.012(.988)$ \\
\hline & & Post & $8.35 \pm 4.48$ & $11.54 \pm 6.59$ & $13.44 \pm 5.60$ & \multirow{3}{*}{$\begin{array}{c}3.214(.000) \\
\text { A | B C }\end{array}$} \\
\hline & & Post-Pre & $-5.74 \pm 2.53$ & $-2.80 \pm 4.86$ & $-0.85 \pm 4.81$ & \\
\hline & & $t(p)$ & $9.898(.002)$ & $2.463(.026)$ & $0.752(.046)$ & \\
\hline & \multirow{4}{*}{$\begin{array}{c}\mathrm{ML} \\
(\mathrm{mm} / \mathrm{s})\end{array}$} & Pre & $9.83 \pm 3.39$ & $9.49 \pm 4.12$ & $9.31 \pm 3.42$ & \multirow[t]{2}{*}{$0.097(.907)$} \\
\hline & & Post & $6.11 \pm 2.66$ & $7.86 \pm 3.67$ & $8.96 \pm 2.96$ & \\
\hline & & Post-Pre & $-3.72 \pm 3.02$ & $-1.62 \pm 2.92$ & $-0.34 \pm 3.34$ & \multirow[t]{2}{*}{$\begin{array}{c}11.575(.000) \\
\mathrm{A} \mid \mathrm{B} C\end{array}$} \\
\hline & & $t(p)$ & $5.366(.001)$ & $2.372(.026)$ & $0.438(.463)$ & \\
\hline & \multirow{4}{*}{$\begin{array}{c}\mathrm{VM} \\
\left(\mathrm{mm} / \mathrm{s}^{2}\right)\end{array}$} & Pre & $29.40 \pm 15.52$ & $30.59 \pm 14.58$ & $31.81 \pm 15.04$ & $0.119(.888)$ \\
\hline & & Post & $20.10 \pm 12.61$ & $26.24 \pm 13.90$ & $32.32 \pm 25.57$ & \multirow{3}{*}{$\begin{array}{c}3.718(.027) \\
\mathrm{A} \mid \mathrm{B} C\end{array}$} \\
\hline & & Post-Pre & $-9.30 \pm 7.29$ & $-4.34 \pm 5.80$ & $0.51 \pm 25.76$ & \\
\hline & & $t(p)$ & $5.563(.001)$ & $3.207(.034)$ & $0.084(.907)$ & \\
\hline
\end{tabular}

${ }^{\mathrm{a}}$ mean \pm standard deviation.

EO, Eye Open; EC, Eye close; AP, Anterior-Posterior sway velocity; ML, Medial-Lateral sway velocity; VM, Sway velocity-moment; WBV group, whole-body vibration plus balance exercise group; BE group, balance exercise group.

these values indicate no appreciable additional fall risk. Nevertheless, significant improvements were observed.

The FRT test, which assesses the limits of stability, revealed improvements of $16 \%$ in the WBV group. A previous study wherein a 3-week intervention was applied to elderly individuals with diabetic neuropathy, an FRT improvement of $9 \%$ was obtained (Richardson et al. 2001). FRT $<25 \mathrm{~cm}$ signals a fall risk; the mean baseline FRT value in this study was about $27 \mathrm{~cm}$, which is close to this cutoff point (Duncan et al. 1990). In the present study, $42.1 \%$ of subjects had FRT $<25 \mathrm{~cm}$ before the intervention; however, this proportion decreased to $16 \%$ after the intervention.

TUG assesses static balance and functional mobility and is used in clinical scales to evaluate elderly and/or neuropathic patients (Persad et al. 2010). Although the
TUG test methodology is straightforward, it includes considerations of function, balance, and mobility (Podsiadlo and Richardson 1991). In the present study, postintervention TUG in the WBV group was decreased by $13 \%$, which was $7 \%$ greater than that observed in the $\mathrm{BE}$ group.

As was observed for static balance, the dynamic balance was also significantly improved in the WBV group following training. The variety of dynamic movements provided in the balance exercise program clearly improved the dynamic balance, and WBV was verified as an element conducive to better results.

In addition to postural balance, lower-limb muscle strength is closely correlated with fall risk (Jin et al. 2009). The lower limb muscles influence postural balance, and reductions in lower-limb muscle strength hinder the 
Table 4. Comparison of one leg stance within groups and between groups $(N=55)$.

\begin{tabular}{|c|c|c|c|c|c|}
\hline & & $\begin{array}{c}\text { WBV group (A) } \\
n=19\end{array}$ & $\begin{array}{c}\text { BE group (B) } \\
n=18\end{array}$ & $\begin{array}{c}\text { control group (C) } \\
n=18\end{array}$ & $\begin{array}{c}\mathrm{F}(p) \\
\text { post hoc }\end{array}$ \\
\hline \multirow{4}{*}{$\begin{array}{l}\mathrm{EO} \\
(\mathrm{sec})\end{array}$} & Pre & $17.64 \pm 6.47^{\mathrm{a}}$ & $17.99 \pm 8.85$ & $18.15 \pm 7.03$ & $0.023(.977)$ \\
\hline & Post & $24.05 \pm 7.79$ & $19.67 \pm 9.87$ & $17.49 \pm 6.91$ & \multirow{3}{*}{$\begin{array}{l}17.116(.000) \\
\mathrm{A}|\mathrm{B}| \mathrm{C}\end{array}$} \\
\hline & Post-Pre & $6.41 \pm 4.59$ & $1.67 \pm 2.49$ & $-0.66 \pm 3.83$ & \\
\hline & $t(p)$ & $6.090(.001)$ & $2.870(.011)$ & $0.735(.473)$ & \\
\hline \multirow{4}{*}{$\begin{array}{l}\mathrm{EC} \\
(\mathrm{sec})\end{array}$} & Pre & $5.38 \pm 3.12$ & $5.27 \pm 3.68$ & $6.15 \pm 3.31$ & $0.369(.693)$ \\
\hline & Post & $7.47 \pm 3.43$ & $6.28 \pm 4.59$ & $5.64 \pm 3.90$ & \multirow{3}{*}{$\begin{array}{l}8.111(.001) \\
\mathrm{A}|\mathrm{B}| \mathrm{C}\end{array}$} \\
\hline & Post-Pre & $2.09 \pm 1.30$ & $1.01 \pm 1.86$ & $-0.52 \pm 2.58$ & \\
\hline & $t(p)$ & $7.001(.001)$ & $2.320(.034)$ & $0.847(.410)$ & \\
\hline
\end{tabular}

${ }^{a}$ mean \pm standard deviation.

EO, Eye Open; EC, Eye close; WBV group, whole-body vibration plus balance exercise group; BE group, balance exercise group.

Table 5. Comparison of dynamic balance within groups and between groups $(N=55)$.

\begin{tabular}{|c|c|c|c|c|c|}
\hline & & $\begin{array}{c}\text { WBV group (A) } \\
n=19\end{array}$ & $\begin{array}{c}\text { BE group (B) } \\
n=18\end{array}$ & $\begin{array}{c}\text { control group }(\mathrm{C}) \\
n=18\end{array}$ & $\begin{array}{c}\mathrm{F}(p) \\
\text { post hoc }\end{array}$ \\
\hline \multirow{4}{*}{$\begin{array}{l}\text { BBS } \\
\text { (point) }\end{array}$} & Pre & $49.47 \pm 2.57^{\mathrm{a}}$ & $48.67 \pm 2.70$ & $50.28 \pm 2.47$ & $1.754(.183)$ \\
\hline & Post & $51.37 \pm 1.80$ & $49.28 \pm 3.23$ & $50.17 \pm 2.50$ & \multirow{3}{*}{$\begin{array}{c}14.271(.000) \\
\mathrm{A} \mid \mathrm{B} C\end{array}$} \\
\hline & Post-Pre & $1.89 \pm 1.52$ & $0.61 \pm 1.20$ & $-0.11 \pm 0.47$ & \\
\hline & $t(p)$ & $5.420(.001)$ & $2.180(.045)$ & $1.002(.331)$ & \\
\hline \multirow{4}{*}{$\begin{array}{l}\text { FRT } \\
(\mathrm{cm})\end{array}$} & Pre & $27.89 \pm 7.52$ & $27.77 \pm 4.02$ & $27.66 \pm 4.23$ & $0.008(.992)$ \\
\hline & Post & $32.35 \pm 6.54$ & $29.91 \pm 4.07$ & $26.98 \pm 2.60$ & \multirow{3}{*}{$\begin{array}{c}11.908(.000) \\
\mathrm{A}|\mathrm{B}| \mathrm{C}\end{array}$} \\
\hline & Post-Pre & $4.45 \pm 3.52$ & $2.13 \pm 3.11$ & $-6.84 \pm 2.29$ & \\
\hline & $t(p)$ & $5.512(.001)$ & $2.929(.010)$ & $0.993(.336)$ & \\
\hline \multirow{4}{*}{$\begin{array}{l}\text { TUG } \\
(\mathrm{sec})\end{array}$} & Pre & $13.31 \pm 2.25$ & $13.66 \pm 2.07$ & $13.43 \pm 1.85$ & $0.132(.877)$ \\
\hline & Post & $11.53 \pm 1.70$ & $12.84 \pm 1.84$ & $13.45 \pm 1.51$ & \multirow{3}{*}{$\begin{array}{c}11.479(.000) \\
\mathrm{A} \mid \mathrm{B} \mathrm{C}\end{array}$} \\
\hline & Post-Pre & $-1.79 \pm 1.09$ & $-0.82 \pm 1.50$ & $0.02 \pm 0.70$ & \\
\hline & $t(p)$ & $7.114(.001)$ & $2.320(.034)$ & $0.101(.921)$ & \\
\hline
\end{tabular}

${ }^{\mathrm{a}}$ mean \pm standard deviation.

WBV group, whole-body vibration plus balance exercise group; BE group, balance exercise group.

Table 6. Comparison of muscle strength within groups and between groups $(N=55)$.

\begin{tabular}{|c|c|c|c|c|c|}
\hline & & $\begin{array}{c}\text { WBV group (A) } \\
n=19\end{array}$ & $\begin{array}{c}\text { BE group (B) } \\
n=18\end{array}$ & $\begin{array}{c}\text { control group }(\mathrm{C}) \\
n=18\end{array}$ & $\begin{array}{c}\mathrm{F}(p) \\
\text { post hoc }\end{array}$ \\
\hline \multirow{4}{*}{$\begin{array}{l}\text { FTSTS } \\
(\mathrm{sec})\end{array}$} & Pre & $17.03 \pm 5.44^{\mathrm{a}}$ & $18.03 \pm 4.61$ & $16.42 \pm 5.01$ & $0.472(.626)$ \\
\hline & Post & $13.35 \pm 4.39$ & $15.92 \pm 4.66$ & $16.91 \pm 4.92$ & \multirow{3}{*}{$\begin{array}{c}11.464(.000) \\
\mathrm{A} \mid \mathrm{B} C\end{array}$} \\
\hline & Post-Pre & $-3.68 \pm 2.40$ & $-1.52 \pm 2.81$ & $0.50 \pm 2.75$ & \\
\hline & $t(p)$ & $6.677(.001)$ & $2.309(.035)$ & $0.766(.455)$ & \\
\hline
\end{tabular}

${ }^{a}$ mean \pm standard deviation.

WBV group, whole-body vibration plus balance exercise group; BE group, balance exercise group. 
maintenance of correct posture and increase fall risk (Persch et al. 2009). In the present study, lower-limb muscle strength was assessed using the FTSTS test, which is considered appropriate for predicting falls in the elderly (Persad et al. 2010). In similar previous studies, two assessment methods for elderly individuals have been used, i.e., (1) counting the number of sit-to-stand cycles in $30 \mathrm{sec}$, and (2) measuring the time required for the FTSTS test, with results of 8-10 times in $30 \mathrm{sec}$ and 12-16 sec for the FTSTS test, respectively (Tiedemann et al. 2008). In the present study, the mean baseline was $17 \mathrm{sec}$, indicating somewhat reduced lower-limb muscle strength. In the WBV group, the post-intervention FTSTS time was improved by $22 \%$; in the BE group, it was improved by $17 \%$. Resistance exercises have been used as an intervention for improving lower-limb muscle strength since a close correlation has been reported between lower-limb muscle strength and fall risk; further, several studies have reported that resistance exercise effectively prevents falls in the elderly (Macaluso and De Vito 2004). Persch et al. (2009) reported that lower-limb muscle training improved muscle strength. Numerous other intervention methods have been applied for the prevention of falls in elderly individuals, and many of these methods reportedly result in improved lower-limb muscle strength (Verghese et al. 2009; Trombetti et al. 2011). The sit-to-stand movements that were included in the balance exercise program of the present study strengthened the lower-limb muscles, in particular, the plantar flexion muscles. Previous studies have reported that adopting a squatting posture during WBV stimulation strengthens the quadriceps muscles, which are knee extensors (Delecluse et al. 2003; Roelants et al. 2004). The improved FTSTS times observed in the present study may also be ascribed to this effect.

Long duration exposure to WBV and high frequency vibration has been shown to have dangerous side effects on the human body, mainly in the lumbar spine but also in the neck and shoulder (Abercromby et al. 2007). Cardinale and Pope (2003) reported that WBV causes increased lumbar spinal degeneration, a higher incidence of low back pain and erector spine muscular fatigue (Cardinale and Pope 2003). Some studies have shown that WBV also has effects on the digestive system, female reproductive organs and peripheral veins. Long-term WBV exposure can contribute to the pathogenesis of disorders of the female reproductive organs (menstrual disturbances, anomalies of position) and disturbances of pregnancy (abortions, stillbirths) (Seidel 1993; Lings and Leboeuf-Yde 2000). To prevent these potentially dangerous side effects, it is important to consider safe exercise protocols when developing exercise programs for elderly patients.

There are several limitations to our study. First, no long-term follow-up data was available after intervention so we did not investigate the long lasting effects. Second, this study was not a double-blinded randomized clinical trial. Evaluations were performed by an assessor blinded to study but the participants were blinded to group allocation. Blinding participants to group allocation was not possible due to the nature of the interventions. Finally, the sample size in this study was small, as a larger sample size may have been a more clear effect of the subject.

Given the advantages of the WBV, which include a short application time and ease of use, this technique could be a highly effective intervention for fall prevention in the elderly, with the additional benefit of improved glycemic control in elderly patients with diabetes. Using a cohort of elderly patients with diabetic neuropathy, the present study verified the beneficial effects of adding WBV to balance exercises, which are considered an effective intervention for fall prevention and improving fall-related parameters.

\section{Acknowledgements}

This study was supported by Sahmyook University.

\section{Conflict of Interest}

The authors declare no conflict of interest.

\section{References}

Abercromby, A.F., Amonette, W.E., Layne, C.S., McFarlin, B.K., Hinman, M.R. \& Paloski, W.H. (2007) Vibration exposure and biodynamic responses during whole-body vibration training. Med. Sci. Sports Exerc., 39, 1794-1800.

Allet, L., Armand, S., de Bie, R.A., Golay, A., Monnin, D., Aminian, K., Staal, J.B. \& de Bruin, E.D. (2010) The gait and balance of patients with diabetes can be improved: a randomised controlled trial. Diabetologia, 53, 458-466.

Bautmans, I., Van Hees, E., Lemper, J.C. \& Mets, T. (2005) The feasibility of Whole Body Vibration in institutionalised elderly persons and its influence on muscle performance, balance and mobility: a randomised controlled trial [ISRCTN62535013]. BMC Geriatr., 5, 17.

Behboudi, L., Azarbayjani, M.A., Aghaalinejad, H. \& Salavati, M. (2011) Effects of aerobic exercise and whole body vibration on glycaemia control in type 2 diabetic males. Asian J. Sports Med., 2, 83-90.

Berg, K.O., Maki, B.E., Williams, J.I., Holliday, P.J. \& WoodDauphinee, S.L. (1992) Clinical and laboratory measures of postural balance in an elderly population. Arch. Phys. Med. Rehabil., 73, 1073-1080.

Cakrt, O., Chovanec, M., Funda, T., Kalitova, P., Betka, J., Zverina, E., Kolar, P. \& Jerabek, J. (2010) Exercise with visual feedback improves postural stability after vestibular schwannoma surgery. Eur. Arch. Otorhinolaryngol., 267, 1355-1360.

Cardinale, M. \& Pope, M.H. (2003) The effects of whole body vibration on humans: dangerous or advantageous? Acta Physiol. Hung., 90, 195-206.

Delbaere, K., Bourgois, J., Van Den Noortgate, N., Vanderstraeten, G., Willems, T. \& Cambier, D. (2006) A home-based multidimensional exercise program reduced physical impairment and fear of falling. Acta Clin. Belg., 61, 340-350.

Delecluse, C., Roelants, M. \& Verschueren, S. (2003) Strength increase after whole-body vibration compared with resistance training. Med. Sci. Sports Exerc., 35, 1033-1041.

Duby, J.J., Campbell, R.K., Setter, S.M., White, J.R. \& Rasmussen, K.A. (2004) Diabetic neuropathy: an intensive review. Am. J. Health Syst. Pharm., 61, 160-173, quiz 175-176.

Duncan, P.W., Weiner, D.K., Chandler, J. \& Studenski, S. (1990) Functional reach: a new clinical measure of balance. $J$. Gerontol., 45, M192-197. 
Era, P., Schroll, M., Ytting, H., Gause-Nilsson, I., Heikkinen, E. \& Steen, B. (1996) Postural balance and its sensory-motor correlates in 75-year-old men and women: a cross-national comparative study. J. Gerontol. A Biol. Sci. Med. Sci., 51, M53-63.

Gillespie, L.D., Robertson, M.C., Gillespie, W.J., Lamb, S.E., Gates, S., Cumming, R.G. \& Rowe, B.H. (2009) Interventions for preventing falls in older people living in the community. Cochrane Database Syst. Rev. CD007146.

Hausdorff, J.M., Rios, D.A. \& Edelberg, H.K. (2001) Gait variability and fall risk in community-living older adults: a 1-year prospective study. Arch. Phys. Med. Rehabil., 82, 1050-1056.

Horlings, C.G., Carpenter, M.G., Honegger, F. \& Allum, J.H. (2009) Vestibular and proprioceptive contributions to human balance corrections: aiding these with prosthetic feedback. Ann. N Y Acad. Sci., 1164, 1-12.

Ishii, T., Yamakita, T., Sato, T., Tanaka, S. \& Fujii, S. (1998) Resistance training improves insulin sensitivity in NIDDM subjects without altering maximal oxygen uptake. Diabetes Care, 21, 1353-1355.

Ites, K.I., Anderson, E.J., Cahill, M.L., Kearney, J.A., Post, E.C. \& Gilchrist, L.S. (2011) Balance interventions for diabetic peripheral neuropathy: a systematic review. J. Geriatr. Phys. Ther., 34, 109-116.

Jessup, J.V., Horne, C., Vishen, R.K. \& Wheeler, D. (2003) Effects of exercise on bone density, balance, and self-efficacy in older women. Biol. Res. Nurs., 4, 171-180.

Jin, H.Y., Kang, Y.M., Kim, C.Y., Kim, S.H., Liu, W.J., Piao, M.H., Park, J.H., Baek, H.S. \& Park, T.S. (2009) Morphological comparison of small nerve fibres in gastric mucosa in nondiabetic and Type 2 diabetic subjects. Diabet. Med., 26, 943-946.

Kruse, R.L., Lemaster, J.W. \& Madsen, R.W. (2010) Fall and balance outcomes after an intervention to promote leg strength, balance, and walking in people with diabetic peripheral neuropathy: "feet first" randomized controlled trial. Phys. Ther, 90, 1568-1579.

Lajoie, Y. (2004) Effect of computerized feedback postural training on posture and attentional demands in older adults. Aging Clin. Exp. Res., 16, 363-368.

Lings, S. \& Leboeuf-Yde, C. (2000) Whole-body vibration and low back pain: a systematic, critical review of the epidemiological literature 1992-1999. Int. Arch. Occup. Environ. Health, 73, 290-297.

Lopopolo, R.B., Greco, M., Sullivan, D., Craik, R.L. \& Mangione, K.K. (2006) Effect of therapeutic exercise on gait speed in community-dwelling elderly people: a meta-analysis. Phys. Ther, 86, 520-540.

Lord, S.R. \& Castell, S. (1994) Physical activity program for older persons: effect on balance, strength, neuromuscular control, and reaction time. Arch. Phys. Med. Rehabil., 75, 648-652.

Lord, S.R., Murray, S.M., Chapman, K., Munro, B. \& Tiedemann, A. (2002) Sit-to-stand performance depends on sensation, speed, balance, and psychological status in addition to strength in older people. J. Gerontol. A Biol. Sci. Med. Sci., 57, M539543.

Macaluso, A. \& De Vito, G. (2004) Muscle strength, power and adaptations to resistance training in older people. Eur. J. Appl. Physiol., 91, 450-472.

Machado, A., Garcia-Lopez, D., Gonzalez-Gallego, J. \& Garatachea, N. (2010) Whole-body vibration training increases muscle strength and mass in older women: a randomized-controlled trial. Scand. J. Med. Sci. Sports, 20, 200-207.

Madureira, M.M., Takayama, L., Gallinaro, A.L., Caparbo, V.F., Costa, R.A. \& Pereira, R.M. (2007) Balance training program is highly effective in improving functional status and reducing the risk of falls in elderly women with osteoporosis: a randomized controlled trial. Osteoporos. Int., 18, 419-425.

Maiorana, A., O’Driscoll, G., Goodman, C., Taylor, R. \& Green, D.
(2002) Combined aerobic and resistance exercise improves glycemic control and fitness in type 2 diabetes. Diabetes Res. Clin. Pract., 56, 115-123.

Maki, B.E., Holliday, P.J. \& Topper, A.K. (1994) A prospective study of postural balance and risk of falling in an ambulatory and independent elderly population. J. Gerontol., 49, M72-84.

Menz, H.B., Lord, S.R., St George, R. \& Fitzpatrick, R.C. (2004) Walking stability and sensorimotor function in older people with diabetic peripheral neuropathy. Arch. Phys. Med. Rehabil., 85, 245-252.

Paltamaa, J., West, H., Sarasoja, T., Wikstrom, J. \& Malkia, E. (2005) Reliability of physical functioning measures in ambulatory subjects with MS. Physiother. Res. Int., 10, 93-109.

Persad, C.C., Cook, S. \& Giordani, B. (2010) Assessing falls in the elderly: should we use simple screening tests or a comprehensive fall risk evaluation? Eur. J. Phys. Rehabil. Med., 46, 249-259.

Persch, L.N., Ugrinowitsch, C., Pereira, G. \& Rodacki, A.L. (2009) Strength training improves fall-related gait kinematics in the elderly: a randomized controlled trial. Clin. Biomech. (Bristol, Avon), 24, 819-825.

Podsiadlo, D. \& Richardson, S. (1991) The timed "Up \& Go": a test of basic functional mobility for frail elderly persons. $J$. Am. Geriatr. Soc., 39, 142-148.

Pollock, R.D., Martin, F.C. \& Newham, D.J. (2012) Whole-body vibration in addition to strength and balance exercise for fallsrelated functional mobility of frail older adults: a single-blind randomized controlled trial. Clin. Rehabil., 26, 915-923.

Pollock, R.D., Woledge, R.C., Mills, K.R., Martin, F.C. \& Newham, D.J. (2010) Muscle activity and acceleration during whole body vibration: effect of frequency and amplitude. Clin. Biomech. (Bristol, Avon), 25, 840-846.

Punakallio, A. (2004) Trial-to-trial reproducibility and test-retest stability of two dynamic balance tests among male firefighters. Int. J. Sports Med., 25, 163-169.

Rees, S.S., Murphy, A.J. \& Watsford, M.L. (2009) Effects of whole body vibration on postural steadiness in an older population. J. Sci. Med. Sport, 12, 440-444.

Resnick, H.E., Vinik, A.I., Schwartz, A.V., Leveille, S.G., Brancati, F.L., Balfour, J. \& Guralnik, J.M. (2000) Independent effects of peripheral nerve dysfunction on lower-extremity physical function in old age: the Women's Health and Aging Study. Diabetes Care, 23, 1642-1647.

Richardson, J.K., Sandman, D. \& Vela, S. (2001) A focused exercise regimen improves clinical measures of balance in patients with peripheral neuropathy. Arch. Phys. Med. Rehabil., 82, 205-209.

Roelants, M., Delecluse, C. \& Verschueren, S.M. (2004) Wholebody-vibration training increases knee-extension strength and speed of movement in older women. J. Am. Geriatr. Soc., 52, 901-908.

Saghaei, M. (2004) Random allocation software for parallel group randomized trials. BMC Med. Res. Methodol., 4, 26.

Schwartz, A.V., Vittinghoff, E., Sellmeyer, D.E., Feingold, K.R., de Rekeneire, N., Strotmeyer, E.S., Shorr, R.I., Vinik, A.I., Odden, M.C., Park, S.W., Faulkner, K.A. \& Harris, T.B. (2008) Diabetes-related complications, glycemic control, and falls in older adults. Diabetes Care, 31, 391-396.

Seidel, H. (1993) Selected health risks caused by long-term, whole-body vibration. Am. J. Ind. Med., 23, 589-604.

Sitja-Rabert, M., Rigau, D., Fort Vanmeerghaeghe, A., RomeroRodriguez, D., Bonastre Subirana, M. \& Bonfill, X. (2012) Efficacy of whole body vibration exercise in older people: a systematic review. Disabil. Rehabil., 34, 883-893.

Snowling, N.J. \& Hopkins, W.G. (2006) Effects of different modes of exercise training on glucose control and risk factors for complications in type 2 diabetic patients: a meta-analysis. Diabetes Care, 29, 2518-2527.

Song, C.H., Petrofsky, J.S., Lee, S.W., Lee, K.J. \& Yim, J.E. (2011) 
Effects of an exercise program on balance and trunk proprioception in older adults with diabetic neuropathies. Diabetes Technol. Ther, 13, 803-811.

Steadman, J., Donaldson, N. \& Kalra, L. (2003) A randomized controlled trial of an enhanced balance training program to improve mobility and reduce falls in elderly patients. J. Am. Geriatr. Soc., 51, 847-852.

Stel, V.S., Smit, J.H., Pluijm, S.M. \& Lips, P. (2003) Balance and mobility performance as treatable risk factors for recurrent falling in older persons. J. Clin. Epidemiol., 56, 659-668.

Tiedemann, A., Shimada, H., Sherrington, C., Murray, S. \& Lord, S. (2008) The comparative ability of eight functional mobility tests for predicting falls in community-dwelling older people. Age Ageing, 37, 430-435.

Tinetti, M.E. (2003) Clinical practice. Preventing falls in elderly persons. N. Engl. J. Med., 348, 42-49.

Trombetti, A., Hars, M., Herrmann, F.R., Kressig, R.W., Ferrari, S. \& Rizzoli, R. (2011) Effect of music-based multitask training on gait, balance, and fall risk in elderly people: a randomized controlled trial. Arch. Intern. Med., 171, 525-533.
Verghese, J., Holtzer, R., Lipton, R.B. \& Wang, C. (2009) Quantitative gait markers and incident fall risk in older adults. $J$. Gerontol. A Biol. Sci. Med. Sci., 64, 896-901.

Volpato, S., Leveille, S.G., Blaum, C., Fried, L.P. \& Guralnik, J.M. (2005) Risk factors for falls in older disabled women with diabetes: the women's health and aging study. J. Gerontol. A Biol. Sci. Med. Sci., 60, 1539-1545.

Von Stengel, S., Kemmler, W., Bebenek, M., Engelke, K. \& Kalender, W.A. (2011) Effects of whole-body vibration training on different devices on bone mineral density. Med. Sci. Sports Exerc., 43, 1071-1079.

Wolf, B., Feys, H., De Weerdt, W., van der Meer, J., Noom, M. \& Aufdemkampe, G. (2001) Effect of a physical therapeutic intervention for balance problems in the elderly: a singleblind, randomized, controlled multicentre trial. Clin. Rehabil., 15, 624-636.

Yamamoto, R., Kinoshita, T., Momoki, T., Arai, T., Okamura, A., Hirao, K. \& Sekihara, H. (2001) Postural sway and diabetic peripheral neuropathy. Diabetes Res. Clin. Pract., 52, 213221. 